\title{
TRADUZINDO LITERATURA DA DIÁSPORA AFRICANA PARA A LÍNGUA PORTUGUESA DO BRASIL: $O$ PARTICULAR, O PÓS-COLONIAL E O GLOBAL
}

\author{
Maria Aparecida Andrade Salgueiro* \\ Universidade do Estado do Rio de Janeiro/FAPERJ
}

\begin{abstract}
Resumo: O presente artigo apresenta breve síntese reflexiva sobre aspecto relevante entre os rumos recentes tomados pelos Estudos de Tradução em sua íntima relação com os Estudos Literários. Partindo de estudos das últimas décadas, que têm mostrado que a tradução não é apenas um processo interlingual, mas fundamentalmente, uma atividade intercultural, procura levantar elementos para a compreensão de como a negritude - ou "o sujeito negro" - se traduz em diferentes contextos e espaços geográficos. Nos espaços lusofônicos a questão é eivada de nuances coloniais e pós-coloniais. Centrando-nos no português do Brasil, buscamos respostas para perguntas como "Quais as implicações de se traduzir literatura afro-americana contemporânea do inglês, com suas formas específicas de questionar identidade, para o português do Brasil?" (ou vice-versa), ou ainda, "Quais são os pressupostos sobre a Literatura Afro-descendente no Brasil e nos Estados Unidos?” Tendo claro que tais questões são bem mais amplas e profundas do que parecem, surgem novas perguntas e reflexão sobre a construção de identidades em diferentes espaços geográficos. Aspectos relacionados à tradução para a língua portuguesa do Brasil de obras afro-americanas (e vice-versa), assim como os contextos político e
\end{abstract}

\footnotetext{
* Formação em Letras (Português-Inglês), Universidade Federal do Rio de Janeiro. Mestrado em Educação, Universidade do Estado do Rio de Janeiro. Doutorado em Letras (Literatura Comparada), Universidade Federal Fluminense. Pós-Doutorado em Estudos de Tradução - Tradução Intercultural, Universidade de Londres, Inglaterra. Professora Associada do Instituto de Letras, Universidade do Estado do Rio de Janeiro. Professora Visitante, AAAS, Dartmouth College, Estados Unidos. Rio de Janeiro, Rio de Janeiro, Brasil. E-mail: cidasal3@gmail.com
} 
cultural que delineiam a seleção, tradução e recepção da literatura traduzida serão centrais na discussão.

Palavras-chave: Literatura. Diáspora Africana. Tradução Intercultural.

\title{
TRANSLATING AFRICAN DIASPORIC LITERATURE TO BRAZILIAN PORTUGUESE: THE LOCAL, THE POST- COLONIAL AND THE GLOBAL
}

\begin{abstract}
The present article presents a brief reflexive synthesis of a relevant aspect raised by recent trends in Translation Studies in their intimate relationship with Literary Studies. Departing from studies from the last decades, which have been showing that translation is not just an interlingual process, but basically, an intercultural activity, this article aims at raising elements for the understanding of how blackness - or the black subject - is translated into different contexts and geographical spaces. In lusophone areas, the issue is full of colonial and postcolonial traits. Focusing on Brazilian Portuguese, we look for answers to questions such as "Which are the implications of translating contemporary African-American Literature from English, with its specific forms of questioning identity, into Brazilian Portuguese?" (or vice-versa), or still, "Which are the assumptions about Afro-descendant Literature in Brazil and in the United States?" Having in mind that such questions are much broader and deep than they actually seem, new questions turn up about the construction of identities in different geographical spaces. Aspects related to the translation of African-American works into Brazilian Portuguese (and vice-versa), as well as political and cultural aspects that shape selection, translation, and reception of translated literature will be central in the discussion.
\end{abstract}

Keywords: Literature. African Diaspora. Intercultural Translation.

O presente artigo apresenta uma breve síntese de rumos recentes tomados pelos Estudos de Tradução no que diz respeito a sua íntima relação com o campo dos Estudos Literários. Não se trata de argüir ou questionar, como querem alguns, se os Estudos de Tradução assim se afastam definitivamente dos Estudos Linguísticos e dessa forma adquirem nova identidade, ou se trata de nova vertente. Não, definitivamente, não objetivamos trabalhar com binarismos. $\mathrm{O}$ mundo, a Arte, a vida são plurais e como tal exigem 
visão bem mais abrangente para que as ditas Ciências Humanas sigam seu rumo esperado de avanços. Objetivamos, neste momento, levantar questionamentos e posicionamentos críticos, visando a suscitar questões e avançar no conhecimento da área através da reflexão e da problematização em língua portuguesa de aspectos variados ligados aos pontos ora em estudo. Na realidade, utilizaremos 'perguntas' concretas em diferentes momentos de nossa exposição, tomando-as, em nosso entendimento, como método de pesquisa verdadeiro e eficaz.

Com pesquisa na área desde os anos 90, particularmente impulsionada por um Pós-Doutorado na Universidade de Londres, nos anos de 2007-2008, com o indispensável apoio do CNPq, sempre buscamos o elo entre a Literatura por nós estudada - a Literatura dos Afro-descendentes, em especial, aquela das Autoras afro-americanas e das afro-brasileiras - e os Estudos de Tradução.

Partindo do ponto em que pesquisas e estudos das últimas décadas têm mostrado que a tradução não é apenas um processo interlingual, mas fundamentalmente, uma atividade intercultural, procuramos levantar elementos para a compreensão de como a negritude - ou 'o sujeito negro' - se traduz em diferentes contextos e espaços geográficos. Nos espaços luso-fônicos a questão é eivada de nuances coloniais e pós-coloniais. Centrando-nos no português do Brasil, buscamos respostas para perguntas como "Quais as implicações de se traduzir literatura afro-americana contemporânea do inglês, com suas formas específicas de questionar identidade, para o português do Brasil?" (ou vice-versa), ou ainda, "Quais são os pressupostos sobre a Literatura Afro-descendente no Brasil e nos Estados Unidos?" Tendo claro que tais questões são bem mais amplas e profundas do que parecem, surgem novas perguntas e reflexões sobre a construção de identidades em diferentes espaços geográficos. Aspectos relacionados à tradução para a língua portuguesa do Brasil de obras afro-americanas (e vice-versa), assim como os contextos político e cultural que delineiam a seleção, tradução e recepção da literatura traduzida são centrais nesta discussão. 
No contexto do mundo contemporâneo, com recorrente representação transcultural de diferentes ordens, tendo em sua agenda a globalização da comunicação, o multiculturalismo, a tradição e a transmissão cultural, são gerados constantes debates ideológicos, emprenhados pela política. Nesse quadro, é nitidamente fundamental o papel da Tradução na difusão da diversidade cultural e inegável que Tradução e Estudos Culturais seguem cada vez mais próximos nos últimos tempos. Aspectos relacionados à tradução para a língua portuguesa de obras afro-americanas, assim como os contextos político e cultural que delineiam a seleção, tradução e recepção da literatura traduzida serão centrais na presente discussão.

Tendo em mente que as áreas com as quais lidaremos neste trabalho, em um mundo de rápidas mudanças, têm levado a uma abordagem interdisciplinar que coloca em escopos bem próximos, e até mesmo, por vezes, em áreas interdependentes, os Estudos de Tradução, os Estudos Culturais, a Literatura Comparada e a Crítica Comparada, todas através do viés da pesquisa identitária, de questões próprias ao multiculturalismo e de abordagens críticas a respeito da globalização, não como bloco monolítico, mas, em seus mais variados aspectos, abrimos nosso enfoque. A pesquisa contemporânea em Literatura, incluindo aqui a grande produção que vem acontecendo após os atentados de 11 de setembro de 2001, tem nos levado a repensar os limites de nossas próprias disciplinas e a retraduzir os conceitos que utilizamos, em busca da recolocação do 'literário', da 'literariedade' e das obras primárias no centro do debate, focos tantas vezes abandonados diante das imposições de preceitos distorcidos a partir dos Estudos Culturais e, por que não dizê-lo, algumas vezes tratados com tantos equívocos.

Passado o tempo em que os Estudos de Tradução realizados nos centros intelectuais dominantes do ocidente se concentravam principalmente na tradução interlingual de textos escritos canônicos, hoje o horizonte é bem mais amplo. Ele abarca a cultura popular, textos multimídia, a linguagem de sinais, assim como as várias tradições tradutórias e interpretativas pelo planeta afora. A disciplina se fragmentou em uma destacada variedade de abordagens, metodologias, 
discursos e redes. Outros campos de estudo e modos de pensar, da hermenêutica e da antropologia até a filosofia e o pós-colonialismo, em sua versão mais recente - pós-pós - colocaram, em primeiro plano, questões fundamentais relativas à tradução e ampliaram seu conceito. Tais desdobramentos afetam qualquer identidade que os Estudos de Tradução possam reivindicar, quer como disciplina secundária quer como programa central de pesquisa.

Focando em nosso ponto de debate neste artigo, podemos afirmar que nosso objeto específico de pesquisa - ou seja, em poucas palavras, a compreensão de como a negritude - ou 'o sujeito negro’ - se traduz em diferentes contextos e espaços geográficos - só recentemente começou a atrair a atenção da Academia, enquanto tópico primário de pesquisa analisado de forma sistêmica por pesquisadores devotados aos Estudos de Tradução.

Nesse sentido citaremos aqui quatro obras recentes - na verdade três delas lançadas em língua inglesa em 2010 - partindo da revisão para a formulação crítica. As obras corajosamente discutem o presente tópico, não exatamente seguindo as mesmas linhas, mas de formas complementares, as quais, em nosso ponto de vista, contribuem para a abertura de novas janelas paradigmáticas no grande escopo dos Estudos Literários da contemporaneidade.

Lauro Maia Amorim, em Translation, Blackness, and The (In) Visible: Harryette Mullen's Poetry in Brazilian Portuguese (AMORIM, 2010), explora a obra da afro-americana Harryette Mullen, poeta, contista e dona de amplo conhecimento literário. Nascida em 1953, é atualmente Professora Associada de Literatura Afro-americana e Criação Literária da Universidade da Califórnia em Los Angeles. Em sua obra, inova e se debate em regozijo com as palavras, criando textos de múltiplos significados e trabalhando tópicos tais como a globalização, o consumismo, a cultura de massas e a política de identidades, o que resulta em obra de difícil decodificação para estadunidenses e de maior dificuldade e desafio ainda para um tradutor que queira transpô-la para uma língua estrangeira.

Em seu esforço - diante da consciência clara das diversidades e tensões a enfrentar - para traduzir poemas de Mullen para um 
publico brasileiro, Amorim traz à tona pressupostos rotineiros, silenciosos, porém, divergentes, em relação ao imaginário de estadunidenses e brasileiros acerca dos afro-descendentes. Na verdade, traz à tona problemas intrigantes relativos à relação entre a Literatura e a negritude através de diferentes culturas. Conflitos específicos, implicações variadas e potencialidades daí decorrentes dão margem a desafiadoras questões estéticas para o trabalho do pesquisador. Seguindo em sua linha de trabalho, no resultado final de sua tradução, Amorim demonstra como são racialmente carregadas várias expressões brasileiras e, mais ainda, como é diversa a construção da negritude nos Estados Unidos e no Brasil. As diferenças chapadas pelas realidades das construções históricas dos dois países, sua relação com os negros ao longo dos tempos, suas formas de lidar com o racismo e o imaginário coletivo daí construído são aspectos que surgem fortes e nítidos, quando se busca traduzir obras com personagens ou temática negra. Assim, à medida que Mullen procura em sua poesia caminhar para um locus que vai além de dimensões unívocas e estáticas de raça, a leitura de brasileiros trará sempre à tona sua própria visão de raça, deixando claros os princípios do já tão estudado "mito da democracia racial".

É exatamente nesse enlace que os Estudos de Tradução têm sido reconhecidos como parte e ao mesmo tempo instrumento da Literatura Comparada, na medida em que a tradução não só permite a compreensão das variáveis reconstruções do "Outro" através de línguas e culturas, como também nos dá as condições necessárias para se visualizar como a própria tradução pode apresentar novas possibilidades de interpretação que podem afetar a forma através da qual leitores da cultura alvo avaliam não apenas uma obra específica de literatura estrangeira, mas, em última instância, a sua própria literatura, também. Questões consideradas invisíveis que, a partir da tradução, tornam-se explícita e escancaradamente visíveis, como aponta Amorim: 
As such, the (in)visible "shop window" of translation makes possible reflections on the inside ("blackness in Brazil", for example) as well as on the outside ("blackness in the United States") in such ways that blackness exists on both sides of the pane of glass: it is at the same time both 'one' and, unexpectedly, the 'other'. (AMORIM, 2010, p. 147)

Em Zora Neale Hurston And Their Eyes Were Watching God: The Construction of an African-American Female Identity and the Translation Turn in Brazilian Portuguese, de Rodrigo Alva e de minha autoria (ALVA; SALGUEIRO, 2010) são explorados traços paralelos aos que acabamos de citar na tradução para o português de Their eyes were watching God, de Zora Neale Hurston, romance escrito em 1937. A obra é considerada um clássico da literatura negra e um dos melhores romances do período, embora Hurston não tenha sido reconhecida em sua época. É um tributo à autoafirmação e à feminilidade negra e a sua busca por identidade, um processo observado através do discurso.

Na obra analítica que publicamos em 2010, após analisar detalhes da tradução do romance de Hurston, intitulada Seus Olhos viam Deus (2004), trabalhamos sobre uma tabela experimental de critérios para realizar a análise da mesma, sob a ótica de muitos dos pontos que já mencionamos neste artigo mais objetivamente. Em outras palavras: a autora do original, Zora Neale Hurston, possuía como uma de suas características literárias peculiares o hábito de transcrever diálogos em suas obras, sempre em busca da valorização da tradição afro-americana oral, ali representada. Em outras palavras, os diálogos no romance procuravam ser transcritos exatamente da forma que os personagens falavam: ou seja, buscava-se a fidelidade aos aspectos fonéticos, deixando-se de lado a ortografia, e a gramática em seu sentido amplo. Como exemplo, citamos o primeiro diálogo da obra, onde se lê: "What dat ole forty year ole 'oman doin' wid her hair swingin' down her back lak some young gal?” (HURSTON, 1998, p. 2), ao invés de, "What is that old forty year old woman doing with her hair swinging down her back like some young girl?" 
O que, à primeira vista, pode ser visto como uma aparente caracterização simplista, na verdade, encerra questões extremamente densas, tais como poder, cultura e origem étnica. A estratégia literária em questão valoriza uma forma de discurso oral utilizada pelos afro-americanos e possui suas origens no passado da escravidão e na opressão sofrida por seus ancestrais. A língua, nesse caso, se fortaleceu como uma maneira de caracterizar um grupo étnico, tanto pelo opressor branco como pela comunidade afro-americana. Para o primeiro, diante dela, encontrava-se uma maneira de impor seu poder dominador, visto que o dialeto não seguia o inglês padrão, o que aparentemente o tornaria menos importante. Para o segundo, era uma maneira de reforçar mais uma característica étnica, valorizar sua cultura e, ao mesmo tempo, de fato, subverter o poder dominante branco.

Assim, sob essa ótica, um ponto importante de discussão em nossa obra foi quão satisfatoriamente essa transposição da oralidade, que é tão representativa de tal população étnica em inglês, foi caracterizada no português do Brasil. Sim, porque não se pode esquecer que no Brasil não temos situação semelhante à que acabamos de descrever. No Brasil a língua falada pelos negros, exceto a de alguns ainda em situação de quilombos, varia de região para região, de estado para estado. Nesse caso específico, nossa busca foi compreender que elementos e conceitos teriam sido levados em consideração pelo tradutor para a tomada de decisões sobre como reproduzir os diálogos originais, as escolhas que ele fez e o que considerou importante para que a oralidade na língua traduzida pudesse também representar um segmento equivalente ao texto original. Na verdade, voltamos ao ponto já mencionado anteriormente: para nossa frustração, observamos que a opção do tradutor foi transcrever os diálogos em português do Brasil em uma formulação que poderíamos rotular primariamente como português incorreto... Ou seja, manifestaram-se aí as visões de raça do tradutor, que seriam estendidas a seus leitores, assim como, perdeu-se toda a perspectiva literária original de Zora Neale Hurston. 
Outra significativa obra neste foco é Translation, Resistance, Activism (TYMOCZKO, 2010), organizada pela pesquisadora da University of Massachusetts, Amherst, Maria Tymoczko. Com ampla produção científica e funcionando como referência na área nos Estados Unidos, a pesquisa levada a cabo naquela Universidade, cujos resultados são publicados por sua Editora Universitária, têm em Maria Tymoczko e Edwin Gentzler seus principais expoentes. Foram eles os Organizadores da obra de referência Translation and Power, no ano de 2002, (TYMOCZKO; GENTZLER, 2002) obra em que seus ensaístas claramente afirmavam não considerar a tradução como uma atividade que ocorre em um espaço neutro, mas sim, em situações sociais e políticas concretas, tendo como artífices, partes com interesses claros tanto na produção como na recepção dos textos para além de fronteiras linguísticas e culturais.

Tais pesquisadores vêem a tradução não como uma simples reprodução fiel de um texto original, mas sim como um processo que invariavelmente envolve atos deliberados de seleção, construção e - omissão. Sim, OMISSÃO, porque aquilo que não é traduzido em um contexto específico é sempre tão revelador quanto aquilo que é traduzido. Ou seja, silêncios e falhas em textos traduzidos - assim como a não tradução (ou, também chamada, tradução zero) de textos inteiros - são aspectos fundamentais e reveladores da política de tradução em contextos culturais específicos. Desta forma, o processo tradutório é algo inextricavelmente ligado a questões de dominação cultural, assertividade e resistência - em síntese, a questões de $P O$ $D E R$. Não são poucos os exemplos ao longo da História que dão conta de tradutores que, em atos de resistência, conseguiram burlar governos, igrejas, editoras e outras instâncias de poder, e usaram a tradução para introduzir novas idéias e formas de expressão.

Sob essa ótica, também é interessante pensar como as omissões, introduções e notas de rodapé informais podem afetar a compreensão na língua alvo. Esses elementos são ferramentas que ajudam o leitor da tradução a se aproximar da experiência original? Ou são paliativos que o tradutor encontra como solução para obstáculos que ele ou ela encararam durante o processo tradutório? Não é possível 
negar que o uso desses artifícios é uma prática bem estabelecida quando falamos de traduções. Há tradutores que preferem inserir uma breve explicação na frase ou parágrafo, em vez de utilizar notas de rodapé; e há aqueles que preferem as notas de rodapé (algumas até demasiadamente longas, perturbando a experiência literária), de maneira a ficarem mais próximos do original. De uma maneira ou de outra, o que isso demonstra é a ativa participação do tradutor no processo de trazer o leitor da língua alvo para mais próximo da experiência que os leitores do original vivenciaram.

Dessa forma, ao reunirmos contribuições da vertente cultural e outras questões teóricas, chegamos a questões metodológicas relevantes para o avanço do tema, como por exemplo, em aspectos de fundamental importância para o mundo luso-fônico: Que relações de poder interferem na escolha de textos a serem traduzidos? Como diferentes culturas constroem a imagem de escritores, textos e culturas a partir das traduções? Qual o papel das traduções na construção dos cânones literários? Como certos textos se tornam fundamentais para a compreensão cultural a partir das fronteiras linguísticas? Qual o papel desenvolvido pela tradução nos processos de construção identitária colonial e pós-colonial?

Se relacionarmos tais pontos a traduções de obras africanas e da diáspora africana, por exemplo, à margem das questões que envolvem hegemonia, relações de poder e consequente exclusão, podemos ainda expandir as questões colocadas: $\mathrm{O}$ que se entende por tradução? De que maneira ela formata a produção literária e a transposição cultural? De que forma a memória cultural oficial contribui para a formatação da tradução? Em diferentes modelos de transmissão cultural, que tipos de paradigmas se destacam?

Tal nos leva, obviamente, a pensar sobre o papel da tradução como estratégia primária da representação cultural no mundo globalizado de hoje, abordando, a partir daí, questões relacionadas à imagem do outro através da tradução, à hegemonia cultural e à globalização, à tradução e à perda e/ou à emergência de cânones literários, à diversidade cultural e às chamadas minorias. Hoje, no caso das narrativas de origem afro - mais especificamente as afro- 
-americanas e as afro-brasileiras - diferentes pontos de reflexão se apresentam, seja pela interseção, seja pelo distanciamento. Somente reflexões calcadas em pressupostos como os da Arqueologia Literária Contemporânea, os Estudos Pós-Coloniais e os que neste artigo apresentamos podem dar resposta a perguntas como "Por que só agora surgem, ou melhor, são visíveis tais narrativas?”

A fim de enfrentar problemas levantados pelos Estudos de Tradução Intercultural, cabe sempre partir de perspectiva interdisciplinar. Não podemos falar de África e da diáspora africana, sem mencionar o papel decisivo que a tradução tem nesta realidade, seja pela visibilidade ou pela invisibilidade. Seja pelas revelações identitárias daí decorrentes. O fundamental é ter clareza das redes de poder aí, mais do que nunca, envolvidas, e lembrar que as relações entre língua e poder ao longo das fronteiras culturais revelam o papel vital da tradução na redefinição dos significados de cultura e identidade étnica.

A propósito, em livro de extremo interesse para a área, publicado na Inglaterra em 2008, o pesquisador Edwin Gentzler discorre sobre tema caro a nosso tópico de pesquisa também. Em sua obra, intitulada Translation and Identity in the Americas - New Directions in Translation Theory (2008), o autor, a que já nos referimos, um dos principais nomes da pesquisa sobre a atividade tradutória intercultural nos Estados Unidos, toca na relevante questão do papel desempenhado pela TRADUÇÃO no próprio desenho e formatação das Américas.

O pesquisador mostra que as Américas são um terreno extremamente fértil - e ainda não explorado - para o campo dos Estudos de Tradução sob a ótica contemporânea. A partir de construção reflexiva e teórica multidisciplinar, demonstra como movimentos ora em curso vem tornando visível e trabalhando no resgate da história multilinguística das Américas e trazendo a público a dura realidade, por tanto tempo escondida, da história de conflito e supressão linguística em todo o continente. Hoje há consciência crescente quanto ao expressivo número de línguas nativas que foram reprimidas e dizimadas durante os processos de colonização, 
quanto à sucessão de gerações de famílias de escravos vindos de África obrigados à força a abrir mão de suas línguas de origem, assim como quanto ao número de imigrantes compelidos a falar suas línguas em segredo, sob pena de punição severa em escolas ou locais de trabalho.

Mostrando que a tradução é um dos meios primários de construção de culturas em vários ambientes pós-coloniais, Gentzler defende que nas Américas trata-se menos de algo que ocorre entre culturas separadas e distintas, mas principalmente algo capaz de ser decisivo no estabelecimento dessas mesmas culturas. Trabalhando com uma variedade de textos e constantemente se referindo a grupos minoritários e oprimidos, sua obra reforça, através de exemplos, o papel cultural que políticas de tradução podem desempenhar em um processo discriminatório, citando como algumas de suas conseqüências a marginalização social, a perda de identidade e o trauma psicológico. Nesse sentido, repensar o passado das Américas significa reavaliar padrões de uso linguístico - e Gentzler, em sua conclusão reafirma a firme convicção de que a História da Tradução nas Américas é na verdade a História da formação da identidade - algo arraigado na psique de seus milhões de habitantes.

Avançando no tema da presente Palestra e reunindo diferentes contribuições teóricas, chegamos a novos questionamentos. Agora nos valemos do tema da 3rd Conference of the International Association for Translation and Intercultural Studies - IATIS (www. iatis.org), que ocorreu em Melbourne, na Austrália, de 8 a 10 de julho de 2009: Mediation and Conflict: Translation and Culture in a Global Context.

Entre alguns dos questionamentos levantados e discutidos naquele momento, selecionamos alguns, entre tantos outros, relevantes para nosso tema: Qual o papel da tradução no relato de conflitos em espaços de diferenças linguísticas e culturais? Como se dá a "tradução intercultural" entre metrópoles e diásporas, ou ainda, entre diásporas? Como tem sido encarado o papel do tradutor (e do intérprete) como agentes/intermediários/avalistas culturais em um mundo transnacional? Como se estabelecem as relações intercultu- 
rais - e seus consequentes impactos políticos - aí considerada, claro, a necessidade de se traduzir $o$ velho e o novo? De que forma se estabelecem as traduções literárias - desafiam e enfrentam a diferença cultural, ou, apenas a reforçam, e se tal, de que forma? Com quais estratégias os meios de comunicação transnacionais facilitam ou desencorajam a compreensão intercultural? Quais algumas das dimensões políticas e ideológicas da tradução? No mundo pós-11 de setembro de 2001, como tem se dado a tradução entre o Ocidente e o Oriente? De que forma pode a grande área das Humanidades contribuir para o avanço de tais questões? E, para finalizar este bloco de questionamentos: Como se colocam os Estudos Literários dentro desse panorama - aí incluídas as discussões sobre o cânone e as relações pós-coloniais, ou ainda, pós-pós coloniais, como querem alguns críticos britânicos? Como se formatam, dentro de tal escopo, as relações transnacionais?

Seja como for, esperamos ter contribuído para a percepção de conclusões de pesquisas em curso e outras recentemente concluídas, nos campos dos Estudos de Tradução e da Literatura Comparada, no que diz respeito à formatação da imagem do OUTRO em suas manifestações étnicas e de gênero. São inúmeros os caminhos que se abrem hoje para alunos, professores e pesquisadores da área de Letras, em especial para aqueles que, de uma forma ou outra, buscam interferência mais concreta na realidade através da Literatura. Considerando como Tymoczko a tradução como resistência $e$ ativismo, fica a formulação clara que, a tradução de, por exemplo, textos contemporâneos relevantes tantas vezes feitos invisíveis, através do enfrentamento dos descobrimentos e utopias do mundo luso-fônico, constitui um belo e fértil campo de trabalho. 


\section{Referências}

ALVA, R.; SAlGUEIRO, M. A. A. Zora Neale Hurston and Their Eyes Were Watching God: The Construction of an African-American Female Identity and the Translation Turn in Brazilian Portuguese. Lexington, KY: LAP - Lambert Academic Publishing, 2010.

AMORIM, L. M. Translation, Blackness, and the (In)Visible: Harryette Mullen's Poetry in Brazilian Portuguese. Lexington, KY: LAP - Lambert Academic Publishing, 2010.

GENTZLER, E. Translation and Identity in the Americas: New Directions in Translation Theory. London: Routledge, 2008.

HURSTON, Z. N. Their Eyes Were Watching God. New York: Harper Perennial Classics, 1998.

. Seus Olhos Viam Deus. Tradução de Marcos Santarrita. Rio de Janeiro:

Record, 2004.

TYMOCZKO, M. (Ed.). Translation, Resistance, Activism. Amherst: University of Massachusetts Press, 2010.

TYMOCZKO, M.; GENTZLER, E. (Ed.). Translation and Power. Amherst: University of Massachusetts Press, 2002.

\section{Bibliografia Consultada}

APTER, E. The Translation Zone: A New Comparative Literature. Princeton: Princeton University Press, 2005.

BASSNETT, S.; TRIVEDI, H. (Ed.). Post-Colonial Translation: Theory and Practice. London: Routledge, 2003.

Cad. Trad., Florianópolis, $n^{0}$ especial, p. 262-276, jul./dez. 2014 
BENEDETTI, I. C.; SOBRAL, A. Conversas com Tradutores: Balanços e perspectivas da tradução. São Paulo: Parábola Editorial, 2003.

BEVERLY, J. Subalternity and Representation: Arguments in Cultural Theory. Durham: Duke University Press, 2004.

GUERINI, A.; TORRES, M. H. C.; COSTA, W. C. (Org.). Literatura traduzida \& literatura nacional. Rio de Janeiro: Editora 7Letras/CNPq, 2009.

HALL, S.; DUGAY, P. (Eds.). Questions of Cultural Identity. London: Sage Publications, 2002.

NEIVA, A. M. A relação entre cor e identidade étnica em traduções brasileiras de um romance norte-americano. In: VASSALO, L. (Org.). Estudos Neolatinos 2, Rio de Janeiro: Programa de Pós-Graduação em Letras Neolatinas / Faculdade de Letras / UFRJ, 1997. p. 531-38.

OTTONI, P. (Org.) Tradução: a prática da diferença. Campinas: Editora da UNICAMP, 1998.

RODRIGUES, C. C. Tradução e diferença. São Paulo: Editora UNESP, 2000.

SCHAFFER, F. C. Democracy in Translation: Understanding Politics in an Unfamiliar Culture. Cornell: Cornell University Press, 2000.

SCHAFFNER, C.; KELLY-HOLMES, H. Cultural Functions of Translation. Cambridge: Multilingual Matters, 1995.

SIMON, S. Gender in Translation: Cultural Identity and the Politics of Transmission. London: Routledge, 1996.

VENUTI, L. The Translator's Invisibility: A History of Translation. New York: Routledge, 1995.

Recebido em: $12 / 02 / 2014$ Aceito em: 23/05/2014 